\title{
KEBUGARAN JASMANI IBU-IBU DI JORONG KP. ALAI NAGARI JAMBAK KECAMATAN LUBUK SIKAPING KABUPATEN PASAMAN
}

\author{
Rika Sepriani $^{1}$, Eldawati $^{2}$, Rosi Oktamarini ${ }^{3}$ \\ ${ }^{1}$ Program Studi Pendidikan Jasmani Kesehatan dan Rekreasi, Fakultas Ilmu Keolahragaan, Universitas \\ Negeri Padang. Jalan Prof. Dr. Hamka Air Tawar Barat, Padang, 25132, Indonesia. \\ ${ }^{2}$ Program Studi Ilmu Keolahragaan, Fakultas Ilmu Keolahragaan, Universitas Negeri Padang. Jalan Prof. \\ Dr. Hamka Air Tawar Barat, Padang, 25132, Indonesia. \\ E-mail: rikasepriani@fik.unp.ac.id ${ }^{1}$
}

\begin{abstract}
Abstrak
Penelitian ini berawal dari keingin tahuan penulis tentang tingkat kebugaran jasmani dari ibu-ibu di Jorong kp. Alai Nagari Jambak Kecamatan Lubuk Sikaping Kabupaten Pasaman. Tujuan penelitian ini adalah untuk mendapat gambaran nyata bagaimana tingkat kebugaran jasmani masing- ibu-ibu tersebut. Jenis penelitian yaitu jenis penelitian deskriptif, Populasi dalam penelitian ini sebanyak 280 orang, dan Sampel diambil dengan teknik purposive sampling sebesar 10\% dengan demikian jumlah sampel adalah 28 Orang ibu rumah tangga Jorong Kp. Alai Nagari Jambak Kecamatan Lubuk Sikaping Kabupaten Pasaman. Jenis data dalam penelitian yaitu data primer berasal dari hasil pengukuran tes kebugaran jasmani terhadap ibu-ibu yang terpilih menjadi sampel dan data sekunder yaitu data ibu-ibu yang diperoleh dari Kantor Wali Nagari Jambak Kecamatan Lubuk Sikaping Kabupaten Pasaman. Kemudian data dianalisis dengan menggunakan teknik analisis data deskriptif. Dari hasil analisis data menunjukkan bahwa tingkat kebugaran jasmani ibu-ibu Jorong Kp. Alai Nagari Jambak Kecamatan Lubuk Sikaping Kabupaten Pasaman memiliki rata-rata sangat kurang . 0 orang ibu rumah tangga dengan kebugaran jasmani baik sekali, dengan persentase $(0 \%)$, 0 orang ibu rumah tangga dengan kebugaran jasmani baik, dengan persentase $(0 \%), 11$ orang ibu rumah tangga dengan kebugaran jasmaninya cukup persentase $(39,28 \%), 5$ orang ibu rumah tangga dengan kebugaran jasmani kurang persentasi $(17,87 \%)$ selanjutnya yaitu kategori kebugaran jasmani ibu rumah tangga sangat kurang sebanyak 5 orang ibu rumah tangga , dengan persentasi $(42,85 \%)$.
\end{abstract}

Kata Kunci: Kebugaran Jasmani

\section{PENDAHULUAN}

Olahraga merupakan kegiatan yang
dibutuhkan oleh setiap orang, dengan
berolahraga orang mendapatkan kesegaran
jasmani, kesegaran pemikirannya dan prestasi
dalam pekerjaannya sehingga dapat
meningkatkan produktivitas kerja. Disisi lain
olahraga juga dapat dijadikan ajang kompetensi
untuk terpacu dalam pencapaian sebuah prestasi,
sebagai wujud untuk mempertahankan prestasi
baik secara individu, kelompok, maupun
Negara.
No. 3 tahun 2005 tentang Sistem Keolahragaan Nasional 21 ayat 4 yang menyatakan bahwa:

"Pembinaan dan pengembangan keolahragaan melalui jalur keluarga, jalur pendidikan, dan jalur masyarakat, yang berbasis pada pengembangan olahraga untuk semua orang yang berlangsung sepanjang hayat". Salah satu arah pembangunan manusia Indonesia ditujukan kepada kegiatan olahraga, sasarannya adalah seluruh lapisan masyarakat, karena bangsa yang sehat jasmani dan rohani yang merupakan aset bangsa yang berharga".

Dari kutipan diatas dijelaskan bahwa masyarakat sangat perlu untuk berolahraga karena dengan berolahraga dapat meningkatkan kebugaran jasmani dan rohani 
sesorang, salah satu hal yang paling penting adalah bagaimana suatu masyarakat selalu terlihat sehat, khususnya para Ibu Rumah Tangga yang harus menjaga kesehatan untuk kelangsungan hidupnya. Pada umumnya Ibu Rumah Tangga tidak mempunyai waktu yang cukup dalam memperhatikan kesehatanya karena sibuk dalam mengurus rumah tangga.

Selain itu juga dijelaskan dalam

Peraturan Menteri Kesehatan Republik Indonesia Nomor 75 Tahun 2014 Pasal 1 ayat 4 yang menyatakan bahwa:

"Upaya kesahatan masyarakat yang selanjutnya disingkat dengan UKM adalah setiap kegiatan untuk memelihara dan meningkatkan kesehatan serta mencengah dan menggulangi timbulnya masalah kesehatan dengan sasaran keluarga, kelompok, dan masyarakat'’

Dari kutipan di atas bahwa pemerintahan dalam meningkatkan kualitas kesehatan masyarakat melalui olahraga menjadi salah satu sasaran untuk mengembangkan dan meningkatkan kebugaran jasmani ibu rumah tangga. berarti usaha sadar dan sistematik melalui promosi dan informasi dalam rangka pendidikan untuk menanamkan kesadaran masyarakat tentang pentingnya arti dan fungsi keolahragaan dalam sistem nilai yang dihayati sehari-hari untuk kemudahan bersama-sama dengan masyarakat melakukan pembinaan kesejahteraan jasmani dan rohani, keluarga maupun seluruh masyarakat dalam rangka pembinaan bangsa pembangunan Negara.

Banyak faktor yang menunjang aktifitas fisik merupakan modal besar dalam kehidupan manusia untuk melakukan aktifitas sehari-hari, salah satu contohnya adalah kegiatan sehari-hari sebagai ibu rumah tangga, pada saat melakukan kegiatan mencuci baju, memasak, menyapu dan kegiatan rumah lainnya. pasti akan sangat membutuhkan energy yang sangat banyak, untuk melakukan kegiatan tersebut, maka harus ada keseimbangan antara asupan gizi dan energy yang dikeluarkan oleh tubuh. Ibu rumah tangga merupakan salah satu kelompok masyarakat yang perlu melakukan olahraga. Sejalan dengan bertambahnya umur, kemampuan fisik maupun mental mulai menurun, tidak mampu lagi melakukan pekerjaan-pekerjaan yang lebih berat, selain itu ibu rumah tangga terlalu Terjadinya peningkatan kebugaran jasmani ibu rumah tangga ditandai dengan adanya perubahan yang terjadi di dalam diri ibu rumah tangga. Perubahan yang dimaksudkan adalah perubahan yang terjadi secara sadar dan tertuju untuk memperoleh sesuatu yang lebih baik dari sebelumnya seperti ibu rumah tangga akan terlihat lebih semangat untuk mengikuti olahraga selanjutnya, dan ibu rumah tangga akan memiliki ketahanan fisik yang baik sehingga mampu untuk berkonsentrasi dalam berbagai kegiatan di dalam rumah tangga, sehingga ibu rumah tangga tidak akan cepat merasakan kelelahan lagi.

Berdasarkan fenomena yang terjadi di lapangan masyarakat Jorong Kp. Alai Nagari Jambak Kecamatan Lubuk Sikaping Kab. Pasaman Di daerah tempat penelitian ini di kelilingi oleh perbukitan dan juga banyaknya persawahan dimana masyarakat melakukan pekerjaanya sejari-hari, di Nagari Jambak Ada tiga Jorong yaitu Jorong Kp Alai, Jorong Induak Gadang dan juga Jorong Caniago. Jarak Jorong Kp. Alai Ke Kota Lubuk Sikaping lebih kurang 2 kilometer. Jumlah Penduduk di Nagari Jambak Kecamatan Lubuk Sikaping Kabupaten Pasaman berjumlah sebanyak 2114 orang, sedangkan Jumlah ibu-ibu yang berada di jorong kampung alai Nagari Jambak Kec. Lubuk Sikaping Kab. Pasaman berjumlah 280 Orang, ibu-ibu yang di Jorong Induak Gadang berjumlah 602 orang, sedangkan di Jorong Caniago berjumlah 182 orang. ibu-ibu juga membantu para suaminya untuk melakukan pekerjaan kesawah maupun kekebun, Karena di daerah Kp. Alai ini mayoritas kehidupan tergantung kepada hasil perkebunan dan juga hasil panen sawah. terlihat bahwasanya banyak sekali ibu rumah tangga melakukan aktifitas fisik yang tidak seimbang dengan kondisi tubuh dan juga melakukan pekerjaan sehari-hari, dan seringkali kelelahan yang berlebihan tanpa diiringi dengan waktu istirahat dan pemenuhan gizi ibu tersebut, tidak menjaga kesehatan tubuhnya demi melakukan pekerjaan rumah misalnya dalam mengurus keluarga dan juga membagi waktu bersama keluarga sehingga kondisi fisik ibu rumah tangga tersebut tidak maksimal atau rendah. Seringkali kesehatan ibu rumah tangga menurun diakibatkan kurangnya istirahat dan juga dipengaruhi oleh banyaknya 
fikiran. Ibu rumah tangga tidak begitu mengutamakan olahraga dikarenakan masih awamnya pengetahuan ibu rumah tangga tentang pentingnya olahraga terhadap tubuh. kebanyakan tingkat pendidikan ibu rumah tangga Jorong kp. Alai Nagari Jambak Kecematan Lubuk Sikaping Kabupaten Pasaman masih banyak yang tamatan SMP.

\section{METODE}

Jenis penelitian ini termasuk jenis penelitian deskriptif, menurut sugiyono (2012:11) yaitu “ penelitian yang dilakukan untuk mengetahui nilai variabel mandiri, baik satu variabel atau lebih tanpa membuat perbandingan, atau menghubungkan antara variabel satu dengan variabel yang lain'. Dengan penelitian deskriptif yakni: kebugaran Jasmani Ibu Ibu di Jorong kp. Alai Nagari Jambak kecamatan Lubuk Sikaping Kabupaten Pasaman.

Populasi dalam penelitian ini adalah seluruh Ibu Ibu yang ada di Jorong Kp. Alai Nagari Jambak Kecamatan Lubuk Sikaping Kabupaten Pasaman yang berjumlah sebanyak 280 orang. Mengingat jumlah populasi diatas dan tercapainya tujuan penelitian maka pengambilan sampel ditetapkan dengan menggunakan teknik, "purposive sampling" yaitu penarikan sampel berdasarkan pertimbangan peneliti. Sedangkan penarikan sampel dalam penelitian ini dilakukan hanya dengan satu jorong diambil untuk menjadi sampel sebesar $10 \%$, Dari jumlah populasi 280 orang. Dengan demikian sampel berjumlah sebanyak 28 orang.

\section{Instrumen Penelitian}

\section{Pelaksanaan Harvard Step Up Test}

Tujuan: mengukur kebugaran jasmani

Alat:

- Tinggi bangku $35 \mathrm{~cm}$ (14 Inchi)

- Papan Tulis

- Stop Watch

- Pena dan Kertas

- Peluit

Cara pelaksanaan tes:

a. Testee berdiri menghadap bangku, pada aba-aba "siap, ya" test dimulai.

b. Naikkan salah satu kaki ke atas bangku dan diikuti kaki berikutnya diletakkan disamping kaki pertama. c. Luruskan kedua tungkai dan punggung lalu melangkah turun dimulai kaki pertama naik dan diikuti kaki berikutnya diletakkan di samping kaki pertama.

d. Cara turun naik bangku ini diteruskan mengikuti irama metronome dengan kecepatan irama 30 kali permenit.

e. Test turun naik bangku ini dilakukan tanpa berhenti selama 3-5 menit.

f. Dibolehkan berganti kaki pertama naik jika salah satu kaki lelah (pergantian dibolehkan selama 3 kali)

g. Jika testee tidak mampu lagi boleh berhenti dan DN dihitung.

h. Setelah aba-aba berhenti diberikan segera duduk di atas bangku dan istirahat.

i. Hitung DN I setelah istirahat I menit selama 30 detik dan catat jumlahnya.

j. Hitung DN ke II selama 30 detik setelah istirahat 2 menit dan catat jumlahnya.

k. Hitung DN III selama 30 detik setelah istirahat 3 menit dan catat jumlahnya.

Indek $=$ Waktu test dalam detik $\times 100$ $2 \times\left(\sum \mathrm{DN} 1+\mathrm{DN}\right.$ II + DN III $)$

NORMA KLASIFIKASI HASIL TES HARVARD

\begin{tabular}{|c|c|c|c|}
\hline NO & $\begin{array}{c}\text { LAKI - } \\
\text { LAKI }\end{array}$ & KLASIFIKASI & PEREMPUAN \\
\hline 1 & $>90$ & $\begin{array}{c}\text { Baik Sekali } \\
\text { (BS) }\end{array}$ & $>86$ \\
\hline 2 & $80-90$ & Baik (B) & $76-86$ \\
\hline 3 & $65-79$ & Sedang (S) & $61-75$ \\
\hline 4 & $55-64$ & Kurang (K) & $50-60$ \\
\hline 5 & $<55$ & $\begin{array}{c}\text { Kurang Sekali } \\
\text { (KS) }\end{array}$ & $<50$ \\
\hline
\end{tabular}

\section{Teknik Analisis Data}

dikumpulkan selanjutnya dilakukan pengelolaan data berdasarkan data yang terkumpul dan telah memenuhi syarat untuk dianalisa, teknik analisa data dilakukan dengan menggunakan teknik distribusi frekwensi (statistikdeskriptif) dengan pehitungan presentase( Yusuf , 2005:40)

\section{HASIL DAN PEMBAHASAN}




\section{HASIL}

Berikut peneliti akan mendeskripsikan hasil penelitian yang peneliti lakukan di Jorong Kp. Alai Nagari Jambak Kecamatan Lubuk Sikaping Kabupaten Pasaman. Sesuai dengan tujuan penelitian yang peneliti lakukan yaitu untuk mengungkap tingkat kebugaran jasmani ibu ibu di Jorong Kp. Alai Nagari Jambak Kecamatan Lubuk Sikaping Kabupaten Pasaman, yang peneliti ambil berdasarkan umur yang dibatasi yaitu 20 sampai 50, Sebelum ditentukan tingkat kebugaran jasmani, terlebih dahulu data yang dikumpulkan dimasukan kedalam daftar nilai tes kebugaran jasmani Harvard step up tes.

NORMA KLASIFIKASI HASIL TES HARVARD

\begin{tabular}{|c|c|c|c|}
\hline N & LAKI - & KLASIFIKA & PEREMPUA \\
O & LAKI & SI & N \\
\hline 1 & $>9$ & $\begin{array}{c}\text { Baik Sekali } \\
(\text { BS })\end{array}$ & $>86$ \\
\hline 2 & $80-90$ & Baik (B) & $76-86$ \\
\hline 3 & $65-79$ & Sedang (S) & $61-75$ \\
\hline 4 & $55-64$ & Kurang (K) & $50-60$ \\
\hline 5 & $<55$ & $\begin{array}{c}\text { Kurang Sekali } \\
\text { (KS) }\end{array}$ & $<50$ \\
\hline
\end{tabular}

Sumber: Arsil. 2015. Evaluasi pendidikan jasmani. Malang: Wineka Media

Berdasarkan norma tersebut, diperoleh hasil pengolahan data penelitian yang dideskripsikan sebagi berikut. a. Kebugaran Jasmani Ibu Ibu di Jorong Kp. Alai Nagari Jambak Kecamatan Lubuk Sikaping Kabupaten Pasaman.

Berdasarkan hasil penelitian diperoleh data sebagai berikut.

Tabel 3.

Distribusi frekuensi Kebugaran Jasmani Ibu Rumah Tangga

\begin{tabular}{|c|c|c|c|c|}
\hline No & Perempuan & $\mathrm{Fa}$ & $\mathrm{Fr}$ & Klasifikasi \\
\hline 1 & $>86$ & 0 & $0 \%$ & Baik Sekali \\
\hline 2 & $76-86$ & & $0 \%$ & Baik \\
\hline 3 & $61-75$ & 11 & $39,28 \%$ & Cukup \\
\hline 4 & $51-60$ & 5 & $17,87 \%$ & Kurang \\
\hline 5 & $<50$ & 12 & $42,85 \%$ & Sangat Kurang \\
\hline & Jumlah & 28 & $100 \%$ & \\
\hline
\end{tabular}

Seperti terlihat pada tabel di atas, hasil perhitungan kebugaran jasmani ibu rumah tangga sebanyak 28 orang dapat dikelompokkan dalam 5 kategori Kebugaran jasmani ibu rumah tangga yaitu yang termasuk dalam kategori kebugaran jasmani ibu rumah tangga baik sekali 0 , dengan persentase $(0 \%)$, kemudian kategori kebugaran jasmani ibu rumah tangga baik 0,dengan persentase (0\%),kategori kebugaran jasmani ibu rumah tangga Cukup sebanyak 11 orang ibu rumah tangga, dengan persentase $(39,28 \%)$, kategori kebugaran jasmani ibu rumah tangga kurang 5 orang ibu rumah tangga dengan persentasi $(17,87 \%)$ selanjutnya yaitu kategori kebugaran jasmani ibu rumah tangga sangat kurang sebanyak 5 orang ibu rumah tangga , dengan persentasi $(42,85 \%)$. Berdasarkan distribusi frekuensi tersebut di atas dapat digambarkan dalam grafik sebagai berikut :

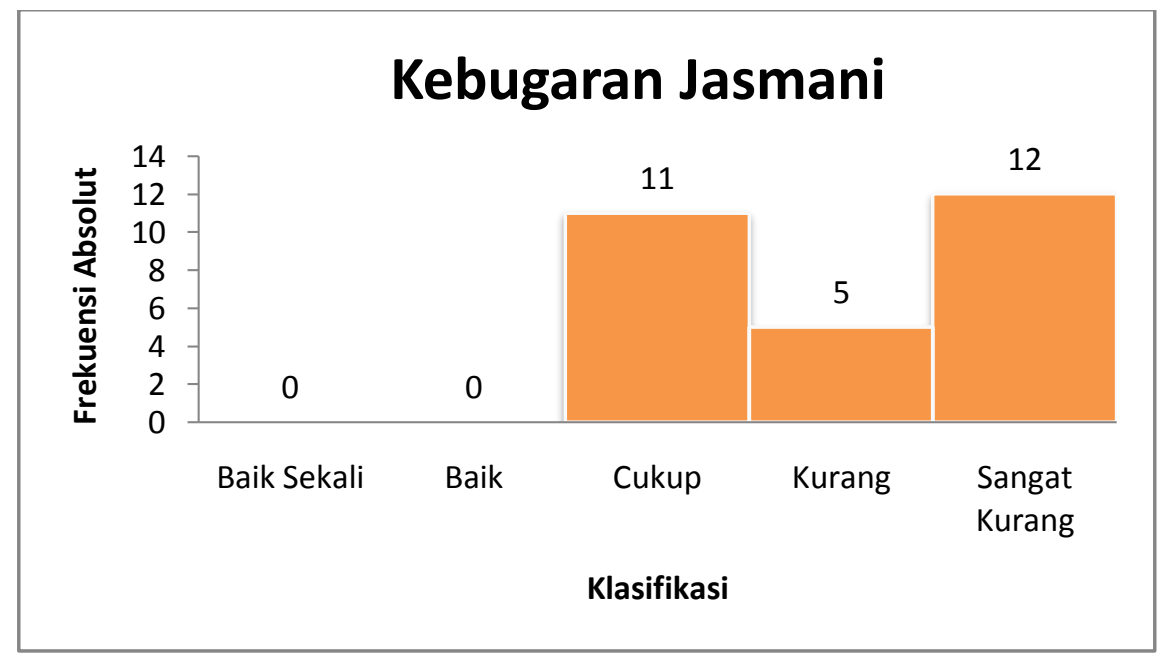




\section{Gambar 1 \\ Diagram distribusi Frekuensi Kebugaran Jasmani Ibu Rumah Tangga Jorong Kp. Alai Nagari Jambak Kecamatan Lubuk Sikaping Kabupaten Pasaman}

\section{Pembahasan}

Berdasarkan hasil penelitian yang telah dipaparkan di atas, maka diperlukan pembahasan lebih lanjut. Hal tersebut untuk memperjelas dan meyakinkan temuan tersebut. Hal-hal yang perlu dibuktikan kebenarannya sesuai dengan pertanyaan penelitian yang telah dikemukakan dan untuk lebih jelasnya jawaban dari pertanyaan penelitian dapat diuraikan sebagai berikut :

Tingkat kebugaran jasmani ibu ibu di Jorong Kp. Alai Nagari Jambak Kecamatan Lubuk Sikaping Kabupaten Pasaman. Berdasarkan hasil analisis data penelitian diperoleh informasi yaitu dari 28 Responden ibu ibu di Jorong Kp. Alai Nagari Jambak Kecamatan Lubuk Sikaping Kabupaten Pasaman, melakukan Tes Kebugaran jasmani diketahui bahwa tidak ada ibu ibu yang berklasifikasi kebugaran jasmani Baik Sekali dan berklasifikasi baik. 11 orang ibu ibu dengan kebugaran jasmaninya cukup (39,28\%), 5 orang ibu ibu dengan kebugaran jasmani kurang $(17,87 \%)$ selanjutnya yaitu kategori kebugaran jasmani ibu ibu sangat kurang sebanyak 5 orang (42,85\%) . Menurut Kusmaedi (2008:93) didalam jurnal kebugaran jasmani mengungkapkan, kebugaran jasmani adalah kemampuan tubuh seseorang untuk melakukan tugas dan perkejaan sehari-hari tanpa menimbulkan kelelahan yang berarti, sehingga tubuh masih memiliki simpanan tenaga untuk mengatasi beban tambahan. Berdasarkan hasil yang diperoleh, sebagian ibu ibu di Jorong Kp. Alai Nagari Jambak Kecamatan Lubuk Sikaping Kabupaten Pasaman yang belum mempunyai tingkat kebugaran jasmani yang baik, banyak faktor yang mempengaruhinya diantaranya adalah aktifitas fisik. Kegiatan sehari-hari sebagai ibu rumah tangga, pada saat melakukan kegiatan mencuci baju, memasak, menyapu dan kegiatan rumah lainnya pasti akan sangat membutuhkan energi yang sangat banyak, untuk melakukan kegiatan tersebut, maka harus ada keseimbangan antara asupan gizi dan energi yang dikeluarkan oleh tubuh. Ibu ibu sebagai ibu rumah tangga merupakan salah satu kelompok masyarakat yang perlu melakukan olahraga. Sejalan dengan bertambahnya umur, kemampuan fisik maupun mental mulai menurun, tidak mampu lagi melakukan pekerjaan-pekerjaan yang lebih berat. Peningkatan kebugaran jasmani ditandai dengan adanya perubahan yang terjadi secara sadar dan tertuju untuk memperoleh sesuatu yang lebih baik dari sebelumnya seperti ibu rumah tangga akan terlihat lebih semangat dan memiliki ketahanan fisik yang baik sehingga mampu untuk berkonsentrasi dalam berbagai kegiatan tidak akan cepat merasakan kelelahan lagi. Kurangnya kebugaran jasmani ibu ibu di Jorong Kp. Alai Nagari Jambak Kecamatan Lubuk Sikaping Kabupaten Pasaman juga dapat dipengaruhi oleh faktor-faktor antara lain : Asupan makanan yang dikonsumsi, kurang nya pengetahuan akan pola hidup sehat dan geografis .

Di samping aktifitas fisik dan asupan makanan, faktor lingkungan juga dapat berpengaruh terhadap tingkat kebugaran jasmani seseorang. Orang yang tinggal didaerah pemukiman warga (desa) biasanya mempunyai kebugaran jasmani yang baik dikarenakan mereka lebih banyak melakukan aktifitas fisik, seperti berkebun dan aktifitas dalam kehidupan rumah tangga Jorong Kp. Alai Nagari Jambak Kecamatan Lubuk Sikaping Kabupaten Pasaman. Tetapi berdasarkan hasil penelitian yang diperoleh oleh peneliti untuk rata-rata kebugaran jasmani ibu rumah tangga Jorong Kp. Alai Nagari Jambak Kecamatan Lubuk Sikaping Kabupaten Pasaman termasuk kedalam klasifikasi kebugaran jasmani yang sangat rendah.

Cara Meningkatkan kebugaran jasmani seseorang salah satunya adalah dengan berolahraga yang benar dan teratur agar tubuh akan terus beradaptasi sesuai dengan kapastitasnya. Sebagaimana yang dinyatakan Lamb dalam Arsil, 2015:8 bahwa orang yang banyak melakukan aktifitas fisik dan olahraga yang teratur maka tingkat kesegaran jasmaninya bertambah baik di banding orang yang kurang 
melakukan aktifitas fisik dan latihan yang teratur.

\section{KESIMPULAN}

Berdasarkan analisis data maka dapat disimpulkan kebugaran jasmani dari 28 Responden ibu ibu di Jorong Kp. Alai Nagari Jambak Kecematan Lubuk Sikaping Kabupaten Pasaman yang telah melakukan Tes kebugaran Jasmani diketahui bahwa tidak ada ibu ibu yang berklasifikasi kebugaran jasmani Baik Sekali dan berklasifikasi baik, 11 orang dengan kebugaran jasmaninya cukup $(39,28 \%), 5$ orang dengan kebugaran jasmani kurang $(17,87 \%)$ dan kebugaran jasmani sangat kurang sebanyak 5 orang $(42,85 \%)$.

\section{DAFTAR PUSTAKA}

Arsil. 2015. Evaluasi Pendidikan Jasmani dan Olahraga. Wineka Media.

Djoko Pekik Irianto. 2006. Bugar dan Sehat dengan Berolahraga. Yogyakarta: Andi Offset

Peraturan Menteri Kesehatan Republik Indonesia Nomor 75 Tahun 2014. Tentang Pusat Kesehatan Masyarakat

Sugiyono 2012. Metode penelitian administrasi, Bandung: Alfabeta

Undang-Undang RI nomor 3 Tahun 2005 Tentang Sistem Keolahragaan Nasional. Bandung: Citra Umbara.

Yusuf. 2005. Metodologi penelitian. Padang: UNP Press 